Check for updates

Cite this: RSC Adv., 2017, 7, 37604

Received 6th May 2017

Accepted 19th July 2017

DOI: $10.1039 / c 7 r a 04984 f$

rsc.li/rsc-advances

\section{Sintered metal fibers@carbon molecular sieve membrane (SMFs@CMSM) composites for the adsorptive removal of low concentration isopropanol}

\begin{abstract}
Yan Shao, (D) *a Huanhao Chen, ${ }^{\text {b }}$ Yibiao Li, ${ }^{a}$ Shan $\mathrm{Xie}^{\mathrm{a}}$ and Bin $\mathrm{Li}^{\mathrm{a}}$
Carbon molecular sieve membranes (CMSM) were fabricated on sintered metal fibers (SMFs) by a template method using resorcinol-formaldehyde resin as precursor. The morphology and textural properties of the as-synthesized SMFs@CMSM composite were characterized by FTIR, BET and SEM, respectively. The adsorption performances of isopropanol in the structured fixed-bed adsorber based on the SMFsaCMSM composites were evaluated. The adsorption dynamic results showed that the mass transfer in the structured fixed-bed has been obviously enhanced via adding the SMFsaCMSM composites in the outlet. The length of unused bed (LUB) theory and Bed Depth Service Time (BDST) model were also applied to further analyze the bed utilization efficiency and adsorption dynamic data.
\end{abstract}

\section{Introduction}

Many environmental and health problems are caused by the emissions of volatile organic compounds (VOCs). ${ }^{1,2}$ Specifically, isopropanol as one of the most important air pollutants, has a toxic effect on human health and causes acute or chronic poisoning to humans by prolonged contact. ${ }^{3}$ Therefore, several methods have been applied to eliminate or recovery VOCs such as absorption, thermal catalytic oxidations, ${ }^{4}$ pervaporation $^{2}$ and photocatalytic oxidation. ${ }^{5}$ Particularly, adsorption based technology has been widely applied to remove VOCs due to its low cost and high-efficiency. ${ }^{3}$ The development of high-efficiency adsorbents has been always considered as one of the key processes in adsorption technology. Various porous materials including activated carbons, ${ }^{6}$ zeolites and resin, ${ }^{7}$ have been applied in the fixedbed adsorber. However, such fixed-bed adsorbers loaded with pelleted adsorbents with large particle size possess several drawbacks including relatively higher mass-transfer resistance and bed pressure drop. Therefore, it is necessary to develop novel structured adsorbent materials that can be applied in the fixedbed adsorber to enhance mass-transfer.

Recently, structured porous materials with low mass/heat transfer resistance, low bed pressure drop and high contacting efficiency have attracted more and more attention, including zeolite coating/sintered metal fibers composites, ${ }^{\mathbf{8 , 9}}$ honeycomb material supported zeolite membranes, ${ }^{\mathbf{1 0}}$ and

${ }^{a}$ School of Chemical and Environmental Engineering, Wuyi University, Jiangmen 52920, PR China. E-mail: wyuchemsy@126.com; Tel: +8607503299397

${ }^{b}$ Mork Family Department of Chemical Engineering and Materials Science, University of Southern California, Los Angeles, CA 90089, USA. E-mail: huanhaoc@usc.edu microfibrous entrapped activated carbons. ${ }^{11}$ Among them, porous sintered metal fibers (SMFs)@inorganic membranes/ coatings composites have been widely designed, fabricated and applied in the field of adsorption and catalysis due to their large surface area, unique porous network structures, excellent mass/heat transfer efficiency as well as thermal/chemical stability. ${ }^{\mathbf{1 2 - 1 4}}$ For example, Chen et $a .^{\mathbf{1 3 , 1 4}}$ designed and prepared gradient SMFs@ZSM-5 zeolite membrane, and also studied its applications in the adsorptive removal and catalytic oxidation of VOCs.

CMSM as one kind of new carbon-based inorganic membrane have a slit-like pore structure, which provides a unique combination of micropore and ultramicropore networks. ${ }^{15,16}$ In addition, CMSM is more conducive to industrial applications due to low cost and simple manufacturing processes comparing with other membrane materials (e.g. zeolite molecular sieve membranes). ${ }^{17}$ Therefore, SMFs@CMSM composites will be promising structured adsorbents/catalysts in the field of adsorption and catalysis. CMSM are usually fabricated via pyrolysis of polymeric precursors, and various polymer precursors have been applied to determine the CMSM's properties and control their pore structures such as polyetherimide $^{18}$ polyimide, ${ }^{19}$ polyfurfuryl alcohol, ${ }^{20}$ phenolic resin. ${ }^{21}$ In particular, resorcinol-formaldehyde resin has been recently demonstrated to be an excellent precursor material for the fabrication of CMSM due to its considerable fixed-carbon yield, high inherent purity and low cost. ${ }^{22}$ On the other hand, ordered mesoporous CMSM with unique and tunable pore structures, high surface areas and mechanical stability can be fabricated by using resorcinol-formaldehyde resin as precursor which can be synthesized via soft templates such as 
amphiphilic surfactants (e.g. pluronic F-127 and P-123). ${ }^{23}$ There is currently no published experimental information regarding the design and fabrication of carbon molecular sieve membranes (CMSM) on the surface of SMFs by using resorcinol-formaldehyde resin as precursor.

This paper aims to develop novel porous SMFs@CMSM composites which can be applied in structured fixed-bed for the low concentration isopropanol removal.

\section{Experimental}

\subsection{Materials}

Sintered metal fibers (SMFs) plates (diameter: $20 \mu \mathrm{m}$; porosity: $0.75 \pm 0.05)$ used as support were supplied by Xian fuerth filter company (China). Resorcinol (R) was purchased from Guangzhou Chemical Reagent Factory. Formaldehyde (F, 37 wt\%) was obtained from Guangzhou Donghong Chemical Factory. Pluronic F-127 $\left(\mathrm{EO}_{106} \mathrm{PO}_{70} \mathrm{EO}_{106}\right)$ was supplied by Sigma-Aldrich Co. LLC. HCl was purchased from Dongguan Shuangde Chemical Co. Ltd. Ethanol (EtOH) was provided by Tianjin Fuyu Fine Chemical Co. Ltd. Deionized water was used in all synthesis process. All of the chemical reagents used in this study were analytical grade.

\subsection{Preparation of SMFs@CMSM composites}

2.2.1. Pretreatment of support. The SMFs support was calcined in air at $550{ }^{\circ} \mathrm{C}$ for $5 \mathrm{~h}$ to form an oxide layer on the stainless steel fibers surface.

2.2.2. Synthesis of resorcinol-formaldehyde resin precursors and coating. The schematic diagram of the preparation of SMFs@CMSM composites can be seen in Fig. 1. Pluronic F127 was added in ethanol solution and stirred until F127 complete dissolution. Resorcinol (R) was dissolved in water. Then the two solutions were mixed and formaldehyde (F) was dropping
Table 1 Synthesis conditions for different samples

\begin{tabular}{llllll}
\hline Recipe no. & $\mathrm{R} / \mathrm{F} 127$ & $\mathrm{R} / \mathrm{HCl}$ & $\mathrm{R} / \mathrm{F}$ & $\mathrm{R} / \mathrm{EtOH}$ & $\mathrm{R} /$ water \\
\hline S1 & $1: 0.005$ & $1: 0.18$ & 1.1 & 8.3 & 16 \\
S2 & $1: 0.002$ & $1: 0.18$ & 1.1 & 8.3 & 16 \\
S3 & $1: 0.007$ & $1: 0.18$ & 1.1 & 8.3 & 16 \\
S4 & $1: 0.005$ & $1: 0.1$ & 1.1 & 8.3 & 16 \\
S5 & $1: 0.005$ & $1: 0.3$ & 1.1 & 8.3 & 16
\end{tabular}

added to the above solution and stirred for $30 \mathrm{~min}$. Finally, $\mathrm{HCl}$ was added as a catalyst to the solution. The molar ratios of the solutions were $0.002-0.007 \mathrm{~F} 127: 8.3 \mathrm{EtOH}: 16$ water $: 1.0 \mathrm{R}$ : $1.1 \mathrm{~F}: 0.1-0.3 \mathrm{HCl}$. After stirring for $6 \mathrm{~h}$, the precursor solution separated into two-phases. The transparent upper phase was ethanol-water rich, which was discarded. The yellow lower phase was polymer-rich resorcinol formaldehyde resin precursors. The pretreated SMFs support was impregnated into it for at least $10 \mathrm{~min}$. Subsequently, the resulting support was preheated in an oven at $90{ }^{\circ} \mathrm{C}$ for $12 \mathrm{~h}$.

2.2.3. Carbonization. The obtained brown polymer membranes were carbonized under a nitrogen atmosphere with the flow rate of $80 \mathrm{~mL} \mathrm{~min}^{-1}$. Calcination was carried out at $400{ }^{\circ} \mathrm{C}$ with a heating rate of $2{ }^{\circ} \mathrm{C} \min ^{-1}$ and held at this temperature for $1 \mathrm{~h}$. Then the temperature was increased to $600{ }^{\circ} \mathrm{C}$ for $2 \mathrm{~h}$ with a heating rate of $2{ }^{\circ} \mathrm{C} \min ^{-1}$. Afterward, the membranes were allowed cooling down to room temperature. The samples were designated as S1 to S5. The details of synthetic conditions and sample names were showed in Table 1.

\subsection{Characterization of SMFs@CMSM composites}

Fourier-transform infrared spectroscopy (FTIR) spectra profiles of the as-synthesized samples were recorded in the 500-4000 $\mathrm{cm}^{-1}$ range using a Vertex70 spectrometer (Bruker Optics,



Fig. 1 The schematic diagram of the preparation of SMFs@CMSM composites. 
Germany) at $4 \mathrm{~cm}^{-1}$ resolution. The $\mathrm{N}_{2}$ adsorption-desorption isotherms were measured at $-196^{\circ} \mathrm{C}$ using Micromeritics tristar 3020 (Micromeritics Instrument Co., USA). All of the samples were preheated at $150{ }^{\circ} \mathrm{C}$ for $8 \mathrm{~h}$. The BET surface area of SMFs@CMSM composites were calculated using the BET (Brunauer-Emmett-Teller) method. The morphologies of SMFs@CMSM composites were also obtained by a FEI/Quanta 400 FEG scanning electron microscopy (SEM).

\subsection{Adsorption dynamics of isopropanol in structured fixed- bed}

The structured fixed bed was filled with granular activated carbons (GACs) (average particle diameter $=1.5 \mathrm{~mm}$ ) with a bed height of $2 \mathrm{~cm}$ in the inlet of fixed bed, and SMFs@CMSM composites (cut into $2 \mathrm{~cm}$ diameter) with a bed height of $1 \mathrm{~cm}$ in the outlet of fixed bed. Specifically, the BET surface area of GACs used in this work is $906 \mathrm{~m}^{2} \mathrm{~g}^{-1} \cdot{ }^{11}$ For comparison purpose, fixed bed with bed height of $3 \mathrm{~cm}$ filled with individual GACs was also designed. The inlet concentrations $\left(C_{0}\right)$ of isopropanol were 2, $2.8,3.6 \mathrm{mg} \mathrm{L}^{-1}$ (mixed with air), respectively, while the volumetric flow rates studied in this work were $3,4,5 \mathrm{~L} \mathrm{~min}^{-1}$, respectively. The inlet and outlet concentrations of isopropanol were monitored using an off-line gas chromatography (Agilent 7890A, USA) equipped with a flame ionization detector (FID) and a HP-5 capillary column with $\mathrm{N}_{2}$ as carried gas.

\section{Mathematical models}

\subsection{The length of unused bed (LUB)}

The LUB value represents the length of the mass transfer zone, which is important in design of adsorption fixed bed. It was estimated by analyzing breakthrough curve:

$$
\mathrm{LUB}=\left(1-\frac{t_{\mathrm{b}}}{t^{*}}\right) L
$$

where $L$ is total bed height $(\mathrm{cm}), t_{\mathrm{b}}$ is the breakthrough time corresponding to $C=C_{\mathrm{b}}$ (where $C / C_{0}=0.05$ ) and $t^{*}$ is the time (min) at which $C / C_{0}=0.5$.

\subsection{Bed Depth Service Time (BDST) model}

The bed depth service time model was first proposed by Bohart and Adams in 1920 in their study on the adsorption of chlorine in charcoal. ${ }^{24}$ The BDST model can be expressed as a linear relationship between the service time and the bed depth by eqn $(2):^{25}$

$$
t=\frac{N_{0} Z}{C_{0} v}-\frac{1}{K_{\mathrm{a}} C_{0}} \ln \left(\frac{C_{0}}{C_{t}}-1\right)
$$

where $C_{0}$ is the inlet concentration $\left(\mathrm{mg} \mathrm{L}^{-1}\right), C_{t}$ is the outlet concentration ( $\left.\mathrm{mg} \mathrm{L}^{-1}\right)$ at time the service time $t(\mathrm{~min}), Z$ is the bed depth $(\mathrm{cm}), v$ is the linear flow rate $\left(\mathrm{cm} \mathrm{min}^{-1}\right), K$ is the adsorption rate constant $\left(\mathrm{L} \mathrm{mg}^{-1} \mathrm{~min}^{-1}\right)$, and $N_{0}$ is the adsorption capacity $\left(\mathrm{mg} \mathrm{L}^{-1}\right)$.

\section{Results and discussion}

\subsection{Characterization analysis}

4.1.1. FTIR. Fig. 2 shows the FTIR spectra of the resorcinolformaldehyde resin polymer and carbon molecular sieve particles prepared using the recipe S1 in Table 1. During the synthesis process, the major reactions between resorcinol and formaldehyde include an addition reaction to form hydroxymethyl derivatives $\left(-\mathrm{CH}_{2} \mathrm{OH}\right)$, and then a condensation reaction of the hydroxymethyl derivatives to form methylene $\left(-\mathrm{CH}_{2}-\right)$ bridged compound. ${ }^{21}$ In addition, the other function of resorcinol is to develop self-assembly structure with F127 by forming stable three-dimensional network structure, which is the rudimental framework of ultimate ordered porous structure in carbon molecular sieve. ${ }^{26}$

As can be seen in the spectrum of original resorcinol-formaldehyde resin polymer in Fig. 2, the reflection bands can be assigned as follows: the $-\mathrm{OH}$ bond $\left(3600-3700 \mathrm{~cm}^{-1}\right),-\mathrm{C}=\mathrm{C}-$ double bond in aromatic rings $\left(1610 \mathrm{~cm}^{-1}\right)$, aromatic $\mathrm{C}-\mathrm{H}(1511$ $\left.\mathrm{cm}^{-1}\right)$, aliphatic $\mathrm{C}-\mathrm{H}\left(1459 \mathrm{~cm}^{-1}\right)$, the $\mathrm{O}-\mathrm{H}$ in-plane deformation $\left(1383 \mathrm{~cm}^{-1}\right)$, the conjunct contribution of the existence of $\mathrm{C}-\mathrm{O}-\mathrm{C}$ or $=\mathrm{C}-\mathrm{O}-\mathrm{C}$ groups $\left(1298\right.$ and $1090 \mathrm{~cm}^{-1}$ ) structure in $\mathrm{RF}$ resin and $\mathrm{F} 127$, and the ring $\mathrm{CH}$ wagging by two adjacent hydrogen in 1,4-substituted benzene $\left(843 \mathrm{~cm}^{-1}\right) .{ }^{26-28}$ For the carbon molecular sieve particle spectrum, most the bands in the spectrum disappeared except for aromatic structure. It can be inferred that nonaromatic atoms gradually decompose from the matrix in the form of $\mathrm{H}_{2}, \mathrm{CO}$, and $\mathrm{CO}_{2}$, etc. In the meantime, the residual structure would be combined and reorganized, leading to the formation of more condensed aromatic structure such as carbon sheet, turbostratic carbon. ${ }^{27}$

4.1.2. $\mathbf{N}_{2}$ adsorption/desorption isotherm. Fig. 3 and 4 show the $\mathrm{N}_{2}$ adsorption/desorption isotherms of SMFs@CMSM composites and the corresponding pore sizes distributions calculated by the BJH method. The surface area, pore diameter and pore volume of the SMFs@CMSM composites are also



Fig. 2 FTIR spectra of resorcinol-formaldehyde resin polymer (a), and carbon molecular sieve 3 particle (b). 



Fig. $3 \mathrm{~N}_{2}$ adsorption-desorption isotherms of the SMFs@CMSM composites.

Table 2 Pore characteristics of SMFs@CMSM composites

\begin{tabular}{lcccc}
\hline Recipe no. & BET $\left(\mathrm{m}^{2} \mathrm{~g}^{-1}\right)$ & $\begin{array}{l}\text { Average pore } \\
\text { diameter }(\mathrm{nm})\end{array}$ & $\begin{array}{l}\text { BJH adsorption } \\
\text { volume }\left(\mathrm{cm}^{3} \mathrm{~g}^{-1}\right)\end{array}$ & $\begin{array}{l}\text { BJH desorption } \\
\text { volume }\left(\mathrm{cm}^{3} \mathrm{~g}^{-1}\right)\end{array}$ \\
\hline S1 & 60.21 & 3.48 & 0.0484 & 0.0477 \\
S2 & 5.72 & 7.85 & 0.0140 & 0.0168 \\
S3 & 13.76 & 11.77 & 0.0253 & 0.0253 \\
S4 & 64.51 & 5.17 & 0.0586 & 0.0692 \\
S5 & 60.01 & 3.96 & 0.0477 & 0.0483
\end{tabular}

presented in Table 2. The $\mathrm{N}_{2}$ adsorption/desorption isotherms indicate the existence of both micropores and mesopores in SMFs@CMSM composites. It can be seen in Fig. 3 that all of the adsorption isotherms present type IV with obvious increasing of adsorbed amount at low relative pressure $\left(P / P_{0}<0.1\right)$, indicating the presence of micropores in these materials. There is a sharp capillary condensation step at intermediate $P / P_{0}$ probably due to the presence of mesopores. Specifically, for materials with pores larger than $c a .5 \mathrm{~nm}$, the width of the hysteresis loop is dependent on their pores quality such as uniformity. For example, MCM-41 with less uniform pore structures usually possesses a relatively broad hysteresis loop. ${ }^{29}$ The existing of hysteresis indicates the mesopores-rich of as-synthesized membrane based adsorbents. For SMFs@CMSM composites,


Fig. 4 Pore size distributions of the SMFs aCMSM composites. 


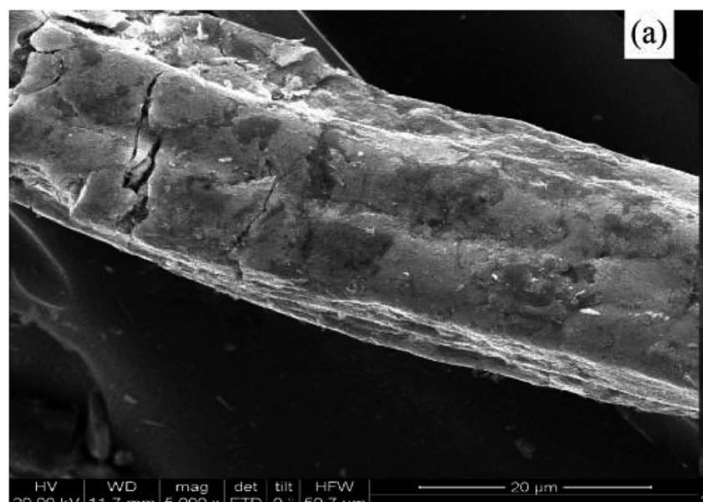

(a)


Fig. 5 SEM micrographs of the SMFs@CMSM composites (a); cross section of the SMFs@CMSM composites: $\times 5000$ (b), $\times 10000$ (c) and $\times 20000$ times (d) magnification.

well-defined $\mathrm{H}_{2}$-type hysteresis loops are observed, which associated with capillary condensation and desorption suggesting the formation of worm-like mesopores. The mesopores will enhance their adsorption capacity as well. The $\mathrm{H}_{2}$-type hysteresis loop of S1 is smaller than the others owing to their relatively small mesopore size (3.48 nm, shown in Table 2). As can be seen in Table 2, the BET surface areas of the SMFs@CMSM composites relied on the amount of template agent (F127) and catalyst (HCl) added. Increasing or decreasing

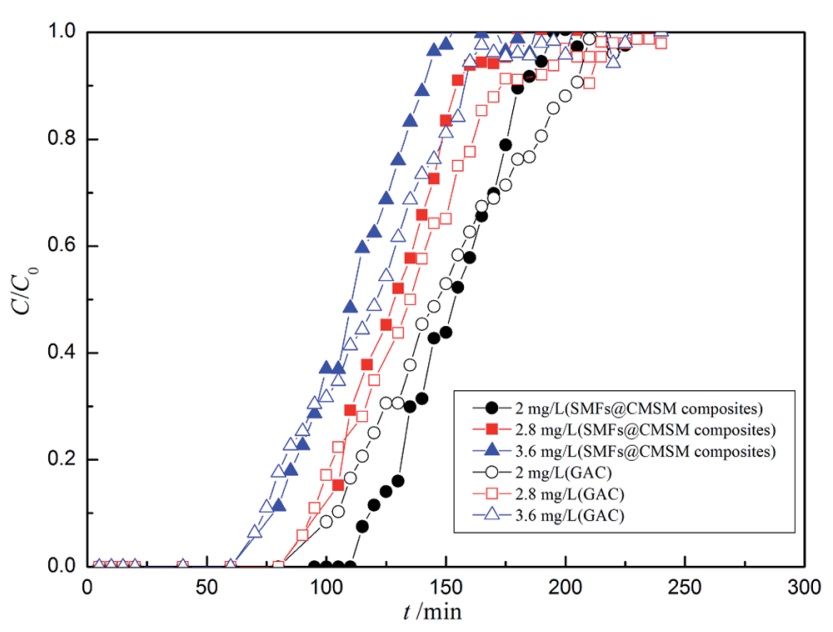

Fig. 6 Breakthrough curves for isopropanol adsorption in structured fixed bed and $3 \mathrm{~cm}$ conventional GACs fixed bed (inlet concentration



the amount of F127 can reduce the surface area and the pore volume. It is appropriate to select R: F127 as $1: 0.005$. Very little change has been observed when the amount of catalyst $(\mathrm{HCl})$ changed according to the BET surface areas of S1, S4 and S5. Hence, the factor of catalyst is less important than that of template agent during the synthesis process. The possible reason is the strategy of polymer (resorcinol-formaldehyde resin) and surfactant (F127) forming an organic-organic interaction and the charged polymer chain interacting with the tails

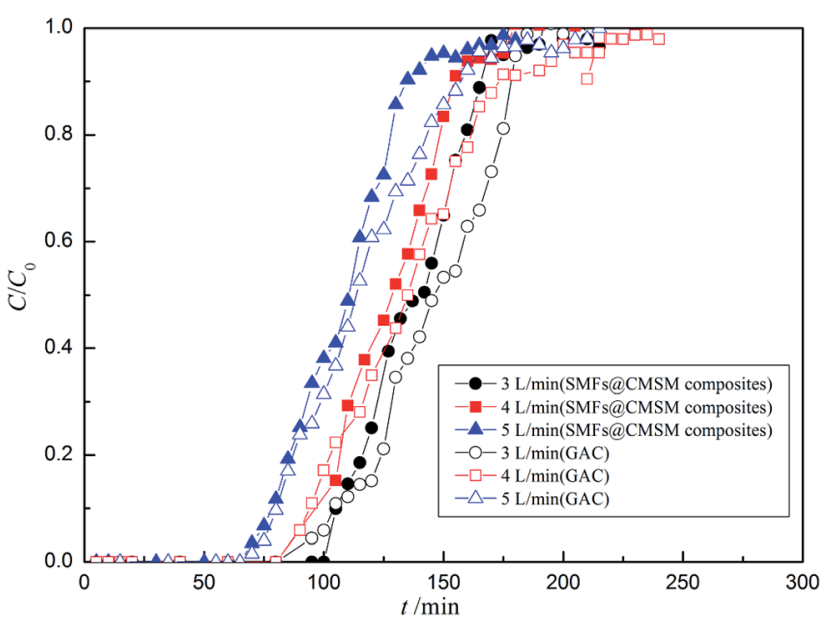

Fig. 7 Breakthrough curves for isopropanol adsorption in structured fixed bed and $3 \mathrm{~cm}$ conventional GACs fixed bed (inlet concentration $=2.8 \mathrm{mg} \mathrm{L}^{-1}$, flow rate $=3-5 \mathrm{~L} \mathrm{~min}^{-1}$ ). 
Table 3 Length of unused bed (LUB) for isopropanol adsorption in fixed beds

\begin{tabular}{|c|c|c|c|}
\hline $\begin{array}{l}\text { Inlet concentration } \\
\left(\mathrm{mg} \mathrm{L}^{-1}\right)\end{array}$ & $\begin{array}{l}\text { Flow rate } \\
\left(\mathrm{L} \min ^{-1}\right)\end{array}$ & Adsorption fixed beds & LUB $(\mathrm{cm})$ \\
\hline \multirow[t]{2}{*}{2} & \multirow[t]{2}{*}{4} & GAC fixed bed & 1.1003 \\
\hline & & Structured fixed bed ${ }^{a}$ & 0.7891 \\
\hline \multirow[t]{2}{*}{2.8} & \multirow[t]{2}{*}{4} & GAC fixed bed & 1.0543 \\
\hline & & Structured fixed bed ${ }^{a}$ & 0.9071 \\
\hline \multirow[t]{2}{*}{3.6} & \multirow[t]{2}{*}{4} & GAC fixed bed & 1.3262 \\
\hline & & Structured fixed bed ${ }^{a}$ & 1.1727 \\
\hline \multirow[t]{2}{*}{2.8} & \multirow[t]{2}{*}{3} & GAC fixed bed & 1.0089 \\
\hline & & Structured fixed bed ${ }^{a}$ & 0.8029 \\
\hline \multirow[t]{2}{*}{2.8} & \multirow[t]{2}{*}{5} & GAC fixed bed & 1.0025 \\
\hline & & Structured fixed bed ${ }^{a}$ & 1.0022 \\
\hline
\end{tabular}

${ }^{a}$ Relative to $3 \mathrm{~cm}$ structured fixed bed filled with $2 \mathrm{~cm}$ GAC in the inlet of bed and $1 \mathrm{~cm}$ SMFs@CMSM composites in the outlet of 2 bed.

of the surfactant. Then a thermally decomposition of the surfactant will form a periodic ordered nanocomposite. ${ }^{30}$ Specifically, in this work, F127 is carbonized by hightemperature calcination under $\mathrm{N}_{2}$ flow to form a carbonaceous pore wall. Therefore, the amount of F127 affects significantly the formation of pore structures in the carbon molecular sieve membranes and their surface areas.

In addition, comparing with our previous work, the BET surface area of SMFs@CMSM composites prepared by the template method with resorcinol-formaldehyde resin precursors are proved to be twice larger than that of composites prepared using PFA/PEG/acetone precursor, the BET surface area of which is only around $30 \mathrm{~m}^{2} \mathrm{~g}^{-1} \cdot{ }^{31}$ Based on the results in Table 2, S1 was selected to do the following test and experiment due to the catalyst playing little effect on the BET surface area.

4.1.3. SEM. Fig. 5(a) shows the SEM image of SMFs@CMSM composites (S1), while Fig. 5(b)-(d) are the crosssectional SEM images of composites. It clearly shows in Fig. 5(a) that the continuous carbon molecular sieve membranes covered on the surface of stainless steel fibers. The assynthesized carbon membranes are relatively compact and smooth with a little slit. The cross-sectional SEM images indicate the membranes were successfully covered on the surface of stainless steel fibers. The thicknesses of the CMSM were about $847.8 \mathrm{~nm}$ and $985.3 \mathrm{~nm}$, respectively.

\subsection{Adsorption dynamics}

4.2.1. Breakthrough curves. The effects of inlet concentration and flow rate on the adsorption breakthrough curves of isopropanol over the structured fixed bed and $3 \mathrm{~cm}$ conventional GACs fixed bed are shown in Fig. 6 and 7, respectively. Specifically, structured fixed bed is filled with $2 \mathrm{~cm}$ GAC in the inlet and $1 \mathrm{~cm}$ SMFs@CMSM composites (S1) in the outlet of fixed bed. Fig. 6 shows the isopropanol breakthrough curves measured using the inlet concentration of $2-3.6 \mathrm{mg} \mathrm{L}^{-1}$ while a fixed flow rate at $2 \mathrm{~L} \mathrm{~min}^{-1}$. Fig. 7 presents the breakthrough curves measured at different gas flow rate $\left(3-5 \mathrm{~L} \mathrm{~min}^{-1}\right)$, but keep the inlet isopropanol concentration constant at $2.8 \mathrm{mg}$ $\mathrm{L}^{-1}$. In Fig. 6 and 7, it is clearly shown that the breakthrough time of isopropanol in two different fixed beds decreased with increasing initial concentration and flow rate, which may be attributed to a quicker saturation of adsorbent in fixed bed at higher inlet concentration and flow rate. Therefore, it can be concluded that the utilization efficiency of adsorbents was decreased with the increasing of inlet concentration and flow rate. As seen in Fig. 6 and 7, it also can be found that the steepness of all breakthrough curves of isopropanol adsorption in structured fixed bed are more upright than those in individual fixed bed at varying concentrations and flow rates. The increasing steepness of breakthrough curves indicates that the mass transfer in the structured bed has been obviously enhanced via adding the SMFs@CMSM composites, which can be attributed to the shorter internal diffusion path of thin carbon molecular sieve membrane. The shorter internal diffusion path obviously reduced solid mass transfer resistance. And the film mass transfer area has also been significantly increased due to the three-dimensional structure of SMFs@CMSM composites. ${ }^{13}$

4.2.2. Determination of LUB. The LUB values were also calculated by analyzing the experimental breakthrough curves of isopropanol in both conventional fixed bed and structured fixed bed according to eqn (1), and the results are listed in Table 3. The LUB value represents bed utilization efficiency. ${ }^{32,33}$ The

Table 4 Parameters of BDST model for isopropanol adsorption in different fixed beds at various flow 1 rates and inlet concentrations

Values of parameters

\begin{tabular}{|c|c|c|c|c|c|}
\hline Inlet concentration $\left(\mathrm{mg} \mathrm{L}^{-1}\right)$ & Flow rate $\left(\mathrm{L} \min ^{-1}\right)$ & Adsorption fixed beds & $N_{0}\left(\mathrm{~g} \mathrm{~L}^{-1}\right)$ & $K_{\mathrm{a}}\left(\mathrm{L} \mathrm{mg}^{-1} \min ^{-1}\right)$ & $R^{2}$ \\
\hline \multirow[t]{2}{*}{2.0} & 4 & GAC fixed bed & 296.82 & 0.02056 & 0.9932 \\
\hline & & Structured fixed bed ${ }^{a}$ & 305.77 & 0.03362 & 0.9931 \\
\hline \multirow[t]{2}{*}{2.8} & 4 & GAC fixed bed & 500.85 & 0.01836 & 0.9903 \\
\hline & & Structured fixed bed ${ }^{a}$ & 476.57 & 0.02457 & 0.9880 \\
\hline \multirow[t]{2}{*}{3.6} & 4 & GAC fixed bed & 423.81 & 0.01319 & 0.9932 \\
\hline & & Structured fixed bed ${ }^{a}$ & 396.90 & 0.01881 & 0.9937 \\
\hline \multirow[t]{2}{*}{2.8} & 3 & GAC fixed bed & 410.74 & 0.02095 & 0.9904 \\
\hline & & Structured fixed bed ${ }^{a}$ & 385.60 & 0.02498 & 0.9884 \\
\hline \multirow[t]{2}{*}{2.8} & 5 & GAC fixed bed & 538.39 & 0.01977 & 0.9948 \\
\hline & & Structured fixed bed ${ }^{a}$ & 504.67 & 0.02490 & 0.9956 \\
\hline
\end{tabular}

${ }^{a}$ Relative to $3 \mathrm{~cm}$ structured fixed bed filled with $2 \mathrm{~cm}$ GAC in the inlet of bed and $1 \mathrm{~cm}$ SMFs@CMSM composites in the outlet of bed. 
larger value for LUB implies the lower bed utilization. As can be seen in Table 3, comparing with conventional GAC fixed bed at the same operating condition, the LUB values for structured fixed bed obviously decreased due to the loading of SMFs@CMSM composites in the outlet. Therefore, it can be concluded that the mass transfer and bed utilization efficiency have been successfully enhanced by adding the SMFs@CMSM composites in the outlet of structured fixed bed. The LUB values for structured fixed bed also increased with the increasing of inlet concentration and flow rate, which is consistent with the breakthrough curves shown in Fig. 6 and 7.

4.2.3. Bed Depth Service Time (BDST) model. The breakthrough curves of isopropanol in both structured fixed bed filled with SMFs@CMSM composites and conventional GAC fixed bed were analyzed by using the BDST model. The BDST model has been widely used to evaluate the bed performance. ${ }^{33,34}$ The values of adsorption rate constant $\left(K_{\mathrm{a}}\right)$ and adsorption capacity $\left(N_{0}\right)$ can be also calculated from the nonlinear fitting. All the values of the parameters together with the correlation coefficients are listed in Table 4 . It can be observed in Table 4 that the values of $K_{\mathrm{a}}$ for structured fixed bed are obviously higher than those of individual GAC fixed bed under same operating condition. And the values of $K_{\mathrm{a}}$ in structured fixed bed also increase with decreasing in gas flow rates and inlet concentrations. The larger adsorption rate indicates mass transfer rate has been obviously enhanced by adding the SMFs@CMSM composites in the outlet of structured fixed bed. These results further explain the phenomenon that the steepness of breakthrough curve of isopropanol in structured fixed bed is more upright than that in conventional GAC fixed bed.

\section{Conclusions}

By fabricating robust porous SMFs@CMSM composites using resorcinol-formaldehyde resin as a carbon precursor, this work demonstrates the applicability of such structured adsorbents in structured fixed-bed adsorber for the removal of low concentration VOCs like isopropanol. The FTIR and SEM characterization results confirmed that the carbon molecular sieve membranes were successfully fabricated on the stainless steel fibers. The thickness of the CMSM is $\sim 900 \mathrm{~nm}$, while the BET surface area is $\sim 60 \mathrm{~m}^{2} \mathrm{~g}^{-1}$ which strongly influenced by the adding amount of template agent. The breakthrough curves of isopropanol over structured fixed-bed adsorber based on SMFs@CMSM composites indicated that the mass transfer was obviously enhanced through adding SMFs@CMSM composites in the outlet of structured fixed bed. The calculated LUB values shown that the utilization efficiency has been enhanced significantly in structured fixed bed. Finally, the adsorption rate constants calculated by BDST model further confirm this phenomenon.

\section{Acknowledgements}

The authors are grateful for the financial support by Guangdong Natural Science Foundation (2014A030310164), Foundation for Distinguished Young Talents in Higher Education of
Guangdong (2014KQNCX158), Foundation of the Department of Education of Guangdong Province (2016KTSCX144), Quality Engineering project of Wuyi University (JG2014025) and Science Foundation for Young Teachers of Wuyi University (2015td01).

\section{References}

1 H. Zaitan, M. H. Manero and H. Valdés, J. Environ. Sci., 2016, 41, 59-68.

2 K. P. Ramaiah, D. Satyasri, S. Sridhar and A. Krishnaiah, J. Hazard. Mater., 2013, 261, 362-371.

3 L. Tang, L. Li, R. Chen, C. Wang, W. Ma and X. Ma, J. Environ. Chem. Eng., 2016, 4, 2045-2051.

4 A. Ikhlaq and B. Kasprzyk-Hordern, Appl. Catal., B, 2017, 200, 274-282.

5 T.-D. Pham and B.-K. Lee, Chem. Eng. J., 2017, 307, 63-73.

6 A. D. Luz, S. M. d. A. Guelli Ulson de Souza, C. da Luz, R. V. d. P. Rezende and A. A. Ulson de Souza, Ind. Eng. Chem. Res., 2013, 52, 7896-7911.

7 F. Xue, Y. Xu, S. Lu, S. Ju and W. Xing, J. Chem. Eng. Data, 2016, 61, 2179-2185.

8 I. Yuranov, A. Renken and L. Kiwi-Minsker, Appl. Catal., A, 2005, 281, 55-60.

9 H. Chen, H. Zhang and Y. Yan, Chem. Eng. Sci., 2014, 111, 313-323.

10 M. A. Ulla, R. Mallada, J. Coronas, L. Gutierrez, E. Miró and J. Santamaría, Appl. Catal., A, 2003, 253, 257-269.

11 Y. Shao, H. Zhang and Y. Yan, Chem. Eng. J., 2013, 225, 481488.

12 H. Chen, Y. Yan, Y. Shao and H. Zhang, AIChE J., 2015, 61, 620-630.

13 H. Chen, H. Zhang and Y. Yan, Chem. Eng. J., 2012, 209, 372378.

14 H. Chen, H. Zhang and Y. Yan, Ind. Eng. Chem. Res., 2012, 51, 16643-16650.

15 Y. Chen and R. Yang, Ind. Eng. Chem. Res., 1994, 33, 31463153.

16 M. B. Hägg, J. A. Lie and A. Lindbråthen, Ann. N. Y. Acad. Sci., 2003, 984, 329-345.

17 P.-S. Lee, D. Kim, S.-E. Nam and R. R. Bhave, Microporous Mesoporous Mater., 2016, 224, 332-338.

18 B. Zhang, Y. Wu, Y. Lu, T. Wang, X. Jian and J. Qiu, J. Membr. Sci., 2015, 474, 114-121.

19 O. Salinas, X. Ma, E. Litwiller and I. Pinnau, J. Membr. Sci., 2016, 500, 115-123.

20 M. Peer, A. Qajar, R. Rajagopalan and H. C. Foley, Microporous Mesoporous Mater., 2014, 196, 235-242.

21 S. Tanaka, T. Yasuda, Y. Katayama and Y. Miyake, J. Membr. Sci., 2011, 379, 52-59.

22 S. C. Rodrigues, R. Whitley and A. Mendes, J. Membr. Sci., 2014, 459, 207-216.

23 Y. Li, B. Yuan, J. Fu, S. Deng and X. Lu, J. Colloid Interface Sci., 2013, 408, 181-190.

24 G. S. Bohart and E. Q. Adams, J. Am. Chem. Soc., 1920, 42, 523-544.

25 D. Wang, N. Chen, Y. Yu, W. Hu and C. Feng, J. Colloid Interface Sci., 2016, 464, 277-284. 
26 B. Zhang, Y. Shi, Y. Wu, T. Wang and J. Qiu, J. Appl. Polym. Sci., 2014, 131, 39925.

27 B. Zhang, G. Shen, Y. Wu, T. Wang, J. Qiu, T. Xu and C. Fu, Ind. Eng. Chem. Res., 2009, 48, 2886-2890.

28 N. Kishore, S. Sachan, K. N. Rai and A. Kumar, Carbon, 2003, 41, 2961-2972.

29 M. Kruk, M. Jaroniec and A. Sayari, Langmuir, 1997, 13, 62676273.
30 Y. Meng, D. Gu, F. Zhang, Y. Shi, H. Yang, Z. Li, C. Yu, B. Tu and D. Zhao, Angew. Chem., 2005, 117, 7215-7221.

31 Y. Shao, H. Chen, Y. Li and X. Ma, Chem. Eng. J., 2015, 276, 51-58.

32 Y. A. Alhamed, J. Hazard. Mater., 2009, 170, 763-770.

33 H. Chen, H. Zhang and Y. Yan, Chem. Eng. J., 2013, 228, 336344.

34 B. Balci, O. Keskinkan and M. Avci, Expert Syst. Appl., 2011, 38, 949-956. 